\title{
Costeadores de impresiones y mercado de ediciones religiosas en la alta Edad Moderna ibérica
}

\author{
Fernando BouzA \\ Universidad Complutense de Madrid \\ ortegal@ucm.es
}

Fecha de recepción: 09/09/2013

Fecha de aceptación: 18/12/2013

\begin{abstract}
RESUMEN
El artículo se propone el estudio de la participación de particulares, ante todo libreros e impresores, en la publicación y circulación de libros de temática religiosa durante los siglos XVI y XVII en el ámbito ibérico. La participación de estos costeadores en el atractivo mercado del libro impreso fue mayor de lo que se ha imaginado. De hecho, en busca de beneficios, se comportaron como agentes muy activos responsables de la edición o reedición de obras, tomando parte en la toma de decisiones que afectan a cuestiones como qué autores y qué obras son editadas, en qué formatos y en qué lenguas. Asimismo, se presentan ejemplos de la participación de clérigos y órdenes en el mercado del libro religioso.
\end{abstract}

Palabras clave: costeadores de impresiones, mercado y comercio del libro religioso impreso, historia de la edición, Alta Edad Moderna Ibérica

\section{Printing investors and the religious book market in the Iberian early modern period}

\begin{abstract}
This article proposes to study the commitment of individual merchants, mainly booksellers and printers, to the edition and trade of religious books in Iberia during the sixteenth and seventeenth centuries. The interest of these investors in the lucrative printed book market was bigger than is usually assumed. As a matter of fact, they behaved as highly active agents and were responsible for making important decisions, including which authors and works were to be published, and which format and language was to be chosen. In addition, the article also presents cases of active involvement of clergymen and religious orders in the market of religious books.
\end{abstract}

Key words: printing investors, religious printed book market and trade, book edition history, Iberian early modern period 
sine me, liber, ibis

Tristia

En septiembre de 1567, en la cancillería regia portuguesa se registraba un alvará por el que se concedía a João de Barreira un privilegio de impresión por ocho años. El tipógrafo se había "concertado" previamente con "os padres do collegio das artes" de Coímbra para "haver de imprimir todas as obras necesarias asy de logica como de filosofia e outras de verso ou proza e algũas orações e grosas e comedias".

A través del impresor, los jesuitas querían ver publicados algunos libros que habían compuesto, así como otros de autores ajenos a su instituto que tenían "emendados de erros e cousas desonestas". Todavía no habían podido introducirlos en la docencia, como les hubiera gustado, pues "se deixarão ate ora de ler por não aver quem os quisesse imprimir e fazer a despeza pera isso necessaria". Dado el uso escolar que se daría a las ediciones, el concierto también incluía la obligación de presentarlas "acomodadas com o espaço necessario pera os ouvientes poderem grosar". Era para proteger el fruto de esa empresa, "cousa de muito custo", para lo que Barreira había solicitado el amparo real ${ }^{1}$.

Ese mismo año, aparecían en Coímbra las Comoediae quatuor de Plauto que João de Barreira hizo posible financiándolas al amparo del concierto con el Colégio das Artes y su privilegio de 14 de septiembre de 1567. Para que "os ouvientes poderem grosar", en efecto, los versos del clásico aparecen separados con un interlineado muy amplio $^{2}$. Y, en la misma portada, junto al inconfundible monograma de la Compañía, se deja constancia de las enmiendas sufridas por las comedias, "ex quibus ea deleta sunt, quae bonis moribus nocere possent" 3 .

Esta edición es un buen ejemplo de lo que Nigel Griffin acertó a llamar el Plautus castigatus jesuítico ${ }^{4}$. Ni que decir tiene que, por supuesto, también evoca lo importante que fue la imprenta en las industrias de la Compañía, así como el papel reservado tanto a las letras clásicas como al teatro en sus propuestas pedagógicas. No obstante, al mismo tiempo, la publicación conimbricense de 1567 revela la presencia de un agente quizá demasiadas veces ignorado: la intervención de João de Barreira como editor. Gracias a su interesada disposición a "fazer a despeza pera isso necessaria" se hicieron realidad las estrategias jesuitas, por supuesto, mucho mejor atendidas.

El presente trabajo intenta acercarse al fenómeno de la publicación y circulación del libro religioso ${ }^{5}$ en la alta Edad Moderna ibérica no desde el punto de vista de sus

1 Deslandes, V.: Documentos para a história da typographia portugueza nos séculos XVI e XVII, Lisboa, Imprensa Nacional, 1888, p. 34. Esta investigación se ha realizado en el marco del proyecto "Prácticas y saberes en la cultura aristocrática del Siglo de Oro: comunicación política y formas de vida", MINECO HAR2011-27177.

2 El ejemplar Res-1620-P de la Biblioteca Nacional de Lisboa (BNL) presenta numerosas glosas manuscritas hechas en esos espacios interlineales. Consultable en http://purl.pt/23120.

3 Plauto, T. M.: Comoediae quatuor. Aulularia. Captivi duo. Stichus. Trinummus, Conimbricae, Apud Ioannem Barrerium, 1567.

4 Griffin, N.: "Plautus castigatus: The Society of Jesus and classical drama”, en Doglio, F., y Chiabò, M. (eds.): I Gesuiti e i primordi del teatro barocco in Europa, Roma, Torre d'Orfeo Editrice, 1995, pp. $257-286$.

5 Esta categoría se usa, por supuesto, a título meramente expresivo. 
contenidos o de su estatuto, sino de su más crasa naturaleza mercantil. En el análisis de este particular negocio editorial se presta atención especial a la actividad desplegada por impresores, libreros y algunos particulares. También a algunas órdenes religiosas que parecen haberse comportado como mercaderes de librería negociando con grandes cantidades de libros. Pero, antes, será necesario trazar un mínimo contexto general en el que enmarcar el negocio editorial impreso del libro religioso en los siglos XVI y XVII ibéricos.

\section{DE LA FE AL NEGOCIO EDITORIAL: EL CREDO EN EL MERCADO DE LOS IMPRESOS}

La relación establecida entre cultura escrita y estado clerical a lo largo de la Edad Moderna fue tan estrecha e íntima como extensa y fructífera. Sin que esto suponga minusvalorar el recurso continuado a voces e imágenes, lo escrito ad vivum o artificialiter llegó a convertirse en un elemento esencial para la autorrepresentación estamental del clero -heredero, defensor y exégeta de una tradición letrada- y para el ejercicio de sus usos y prácticas instrumentales.

En el mundo romano, el Concilio de Trento reforzó de forma definitiva los términos de dicha relación al definir la reforma del sacramento del orden, pues en su sesión XXIII (1563) prescribió que no podrían recibir la prima tonsura "quique legere, \& scribere nesciant" (Decretum de reformatione, caput IV). Interpretaciones posteriores supusieron que a los tonsurados les "bastará que sepan leer en su idioma, aunque no sepan leer en Latín" y que "no es necessario que escriuan bien, sino basta que de

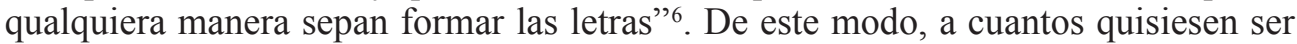
ordenados les resultaba imprescindible demostrar un conocimiento letrado, aunque éste fuese mínimo y, en consecuencia, la absoluta falta de letras fue considerada una de las formas de irregularidad por defecto "del alma" que impedían recibir órdenes y tomar estado entre los clérigos.

Un estamento en el que resultarían omnipresentes el aprendizaje y la práctica de las letras, incluidas ahora también, por supuesto, las latinas. El particular cursus vitae clerical podía suponer, de hecho, recorrer el largo camino que media entre una prima tonsura apenas alfabetizada en lengua vulgar y la ostentación erudita de los auctores tenidos por excelsos y cuyo nombre se dejaba oír en las esquinas de las cuatro partes del mundo gracias a la imprenta.

La consideración del impacto que lo tipográfico tuvo sobre la expresión de lo religioso y su específica comunicación a lo largo de la alta Edad Moderna tiene una enorme y especial relevancia ${ }^{8}$. De forma paulatina, la experiencia religiosa sufrió

6 Montes de Porres, A.: Suma Diana recopilado en romance, En Madrid, por Melchor Sánchez. A costa de Gabriel de León, Mercader de Libros y Diputado de los Hospitales Reales desta Corte, 1657, p. 577.

7 Busenbaum, H.: Médula de la teología moral, En Madrid, Por Bernardo de Villadiego. A costa de Santiago Martín Redondo, Mercader de Libros, 1667, p. 501.

8 Para la síntesis siguiente, remitimos a BouzA, F.: "Leer para creer. Religión y cultura del libro en la Edad Moderna", en CorTés PeÑA, A. L. (ed.), Historia del cristianismo. III. El mundo moderno, Trotta-Universidad de Granada, Madrid, 2006, pp. 637-679; Pérez GARCíA, R. M.: La imprenta y la literatura espiritual castellana 
una conveniente acomodación expositiva a las formas nuevas de la cultura escrita, incorporando de manera inmediata analogías de la mecánica tipográfica. Al mismo tiempo, los impresos se hicieron presentes en los más variados ámbitos, del cotidiano despacho eclesiástico a la definición dogmática y doctrinal y, claro está, a su correlato en forma de censura y excomunión, pasando por las labores de información y comunicación.

En las diócesis ibéricas, un sinfín de formularios y otros impresos menores facilitaron la vasta gestión institucional en materias de administración eclesial, al tiempo que las receterías (no libros) servían a las prácticas devocionales particulares y las prensas garantizaban la ortodoxia ritual del nuevo rezado. De un lado, un género moderno como el de las cartas pastorales a los fieles testimoniaba una forma renovada de articular la relación entre los prelados y las comunidades a su cuidado y, de otro, las industrias misionales reforzaban su ya impresionante batería de medios con toda clase de productos tipográficos. La imprenta permitía disponer de misiones sordas donde la voz del predicador era sustituida por su copia tipográfica, que sería leída, u oída leer, después de terminada la misión o allí donde los apóstoles no pudieran llegar.

Por supuesto, las grandes polémicas entre credos y las numerosas disputas abiertas dentro de la propia confesión católica, por ejemplo entre sus combativas órdenes, le sacaron el mayor partido posible a los recursos difusionistas de la imprenta. Ésta coadyuvó, así, a la constitución de una respublica sacrarum litterarum, coronada por un peculiar parnaso de eruditos auctores que alcanzaban en vida la notoriedad pública internacional que sólo podía conceder la tipografía con su imparable movimiento de títulos y ediciones.

Además de que también hubo clérigos tipógrafos ${ }^{9}$ y que varias iglesias o comunidades protegieron celosas los privilegios exclusivos de edición de algunos impresos de gran tirada con los que habían sido beneficiadas ${ }^{10}$, las prensas no faltaron en claustros, palacios episcopales y $\operatorname{colegios}^{11}$. Por otro lado, la parte más numerosa de los autores de obra nueva entonces publicados mantuvieron alguna

en la España del Renacimiento, 1470-1560. Historia y estructura de una emisión cultural, Gijón, Trea, 2006; Palomo, F.: "Limosnas impresas. Escritos e imágenes en las prácticas misioneras de interior en la península Ibérica (siglos XVI-XVII)", Manuscrits, 25 (2007), pp. 239-265; CuRTo, D. RAMADA: Cultura escrita (séculos XV a XVIII), Lisboa, Imprensa de Ciências Sociais 2007; Álvarez Santaló, L. C.: Así en la letra como en el cielo. Libro e imaginario religioso en la España moderna, Madrid, Abada, 2012; RuEdA, P.: El libro en circulación en el mundo moderno en España y Latinoamérica, Madrid, Calambur, 2012.

9 El más célebre fue el dominico Diego García, activo entre 1651 y 1672 en Alcalá y Burgo de Osma. Delgado Casado: J.: Diccionario de impresores españoles (siglos XVI-XVII), Madrid, Arco/Libros, 1996, I, pp. 251-252.

10 ReYES, F. DE LOS: El libro en España y América. Legislación y censura (siglos XV-XVIII), Madrid, Arco/ Libros, 2000, I, pp. 55-78, 211-227.

11 Junto a las imprentas de los colegios dominicos de San Vicente Ferrer de Zaragoza y de Santo Tomás de Alcalá y a las instaladas en los de la Compañía en Valencia, Sevilla, Madrid, Valladolid, Cádiz, Macao o Manila, en los siglos XVI y XVII, hubo prensas en funcionamiento, al menos, en los conventos de San Esteban (Salamanca), San Pablo (Valladolid), San Francisco (Barcelona), San José (Uclés), San Francisco (Gerona), Nuestra Señora del Remedio y el Carmen (Valencia), San Francisco (Murcia), San Agustín (Orihuela), San Francisco (Sevilla), San Agustín (México) o Santo Tomás (Manila), así como en los monasterios de San Pedro Mártir (Toledo), La Vid, Fitero, Irache, San Juan de la Peña, San Benito (Sahagún), la Victoria, San Jerónimo el Real y San Martín (Madrid), Nuestra Señora del Prado (Valladolid), São Vicente de Fora (Lisboa) y Santa 
clase de vinculación con la condición eclesiástica, siendo el clero por excelencia un estado no ya de lectores, sino también de escritores. Esto por no entrar en que la edición o reedición de auctoritates católicas, así como de textos relativos a liturgia, devoción, pastoral, doctrina o moral, ocupaba a una parte no pequeña de los talleres tipográficos.

Los géneros y materias vinculados de una forma $u$ otra al inmenso espectro textual de lo religioso llegaron a constituir, sin duda, una de las partes relativamente más importantes del negocio editorial ibérico durante la alta Edad Moderna. Así lo prueban obviamente fuentes diversas, como los inventarios de bibliotecas, los registros del comercio librero o los repertorios tipobibliográficos de los centros de producción que, peninsulares o no, abastecían al mercado metropolitano e imperial portugués y español.

El carácter venal, característico de los productos impresos, afectaba a cuantas obras se convertían en mercancía al pasar por las prensas. Es cierto que los impresos no pagaban alcabala, pero sí estaban sometidos a la tasa, cuya fijación era obligatoria para la venta pública de libros. En este sentido, es revelador que ésta no discrimine en el conjunto de los impresos ni por su materia, religiosa o no, ni tampoco por el estado de sus autores. Y, por supuesto, también los eclesiásticos se preocuparon por conseguir que los precios de sus obras fuesen los más altos posibles, como demuestran los expedientes de petición de tasa nueva que algunos de ellos presentaron, por ejemplo ante el Consejo de Castilla, tras mostrar su desacuerdo con las establecidas por éste ${ }^{12}$.

También podían, de otro lado, garantizarse las mejores condiciones para la venta de las obras que habían compuesto o promovido, como se muestra en el caso de la edición de Johannes Molinaeus del Decretum del canonista medieval Ivo de Chartres para la que Bartholomeus van Grave (Gravius), "libraire" de Lovaina, obtuvo en 1561 privilegio de impresión y venta en los Países Bajos ${ }^{13}$.

Durante su estancia en la corte de María Tudor, el franciscano Bernardo de Fresneda, a quien la edición lovaniense está dedicada, "huuo en Inglaterra todos los decretos de Ibon Carnotense [Ivo de Chartres] scriptos de mano, y viendo que nunca se hauían impresso procuró estando en flandres que fuessen vistos y corregidos por hombres muy doctos de su orden y por el doctor [Johannes] Molineo" ${ }^{14}$. Desde Toledo, en agosto de 1560, el confesor real medió ante el Cardenal Granvela para que se concediesen los permisos preceptivos para publicarlo en las mejores condiciones, pues Molinaeus "me scriuió que ya tenía visto y examinado el exemplar que

Cruz (Coímbra), sin olvidar las tipografías instaladas en las casas episcopales de Almería, Orihuela y Burgo de Osma.

12 Bouza, F.: Dásele licencia y privilegio. Don Quijote y la aprobación de libros en el Siglo de Oro, Madrid, Akal, 2012, pp. 146-147.

13 Ivo De Chartres: Decretum, Lovanii, Excudebat Bartholomaeus Grauius Typographus Iuratus sibi, \& haeredibus Arnoldi Birckmanni, 1561, "Copie du Priuilege", Bruselas, 2 de agosto de 1561, preliminares sin foliar. Sobre la historia editorial del Decretum en el XVI, Rolker, C.: Canon Law and the Letters of Ivo of Chartres, Cambridge, Cambridge University Press, 2009.

14 Privilegio de impresión y venta para Aragón concedido a Gravius del Decretum de Ivo de Chartres, Madrid, 9 de agosto de 1561, Archivo de la Corona de Aragón, Barcelona (ACA), Archivo Real, Real Cancillería, Registros, Felipe I el Prudente, Diversorum, 2, fols. 133v.-135r. 
yo le dexé de los decretos de Ibon carnotense, y questaua concertado con el impresor Grauio que lo imprimiese como le diesen previlegio". No obstante, Van Grave imponía una condición especial: "que yo fuese obligado a tomalle quatrocientos exemplares, y esto haré de buena gana" 15 .

Ya en el privilegio flamenco se dejaba constancia de que "le dict liure est merueilleusement grande $\&$ de grosse despence" ${ }^{16}$, por lo que, para cumplir con su compromiso con el editor, Bernardo de Fresneda pidió a Felipe II garantías de que no se pudiesen vender ejemplares del Decretum hasta que se agotasen aquellos cuatrocientos que tenía comprometidos. El franciscano le representó, como se puede leer en la tramitación para Aragón, que "porque el dicho impressor Grauio tomasse a cargo la impressión le prometistes que trabajaríades que en estos Reynos no se vendiesse ningún libro de los dichos decretos hasta que se huuiessen vendido quatrozientos volúmenes de libros dellos" ${ }^{17}$. Así fue concedido, señalándose que no se vendiese en Aragón ningún ejemplar del Decretum, ni siquiera por el propio Gravius ${ }^{18}$, hasta que se agotasen los del fraile franciscano, que éste rubricaría para su conveniente identificación.

Quizá no así en el caso del Decretum de Ivo de Chartres, pero el negocio editorial del libro religioso podía llegar a ser bastante lucrativo, en especial cuando las tiradas eran elevadas y su consumo estaba asegurado. Así, el interés por hacerse con una parte del suculento comercio de los libros del nuevo rezado atrajo la atención de los Ruiz medinenses y de sus parientes los mercaderes burgaleses Francisco y Juan de la Presa, quienes hicieron traer de Francia una serie de prensas y un buen número de oficiales para moverlas ${ }^{19}$. Pero, siendo tan pingüe el beneficio que cabía esperar, no era necesario ser financiero o mercader para interesarse por el negocio de la impresión.

Como se señala en los preliminares de la obra publicada en Madrid por Alonso Gómez, el cardenal Gaspar de Quiroga concedió al secretario Mateo Vázquez la licencia y el privilegio de impresión y venta del Index et catalogus librorum prohibitorum que él mismo había impulsado como Inquisidor General ${ }^{20}$. El texto de la merced que se imprimió va fechado en Madrid, a 20 de mayo de 1583, pero en los registros del Consejo de Inquisición se asentó ya el 2 de agosto de 1582 que "V.Sa Illma. [Quiroga] haze gracia de la impressión del cathálogo al sr. Matheo Vázquez" para "que pueda encargar la dicha impressión a la persona que le paresciere y gozar y llevar el interese

15 Carta de Bernardo de Fresneda al Cardenal Granvela (Toledo, 9 de agosto de 1560), Real Biblioteca, Madrid, Ms. II/2291. Cito por http://avisos.realbiblioteca.es/?p=article\&aviso=32\&art=980 .

16 Ivo de Chartres, op. cit. (nota 13), "Copie du Priuilege”, preliminares sin foliar.

17 Privilegio a Bernardo de Fresneda sobre la venta privilegiada de ejemplares del Decretum de Ivo de Chartres, Monzón, 22 de diciembre de 1564, ACA, Archivo Real, Real Cancillería, Registros, Felipe I el Prudente, Diversorum, 4, fols. 58v.-59v.

18 Desde 1561, disponía de privilegio para la Corona de Aragón, véase nota 14.

19 Fernández Valladares, M.: La imprenta en Burgos (1501-1600), 2 vols., Madrid, Arco/Libros, 2000, I, pp. 216-225. Griffin, C.: Oficiales de imprenta, herejía e Inquisición en la España del siglo XVI, Madrid, Ollero y Ramos, 2009, p. 214.

20 " [...] mandamos y prohibimos, que ninguno sea osado a hazer imprimir, ni imprima, trayga impresso de fuera destos Reynos, ni tenga, ni venda este dicho Catálogo, e Índice, saluo Matheo Vázquez, Secretario de su Magestad, de la santa general Inquisición, o quien su poder ouiere", Index et catalogus librorum prohibitorum, Madriti, Apud Alphonsum Gomezium Regium Typographum, 1583, preliminares sin foliar. 
que della resultare como cosa suya propia"21. Sobre esa base, Mateo Vázquez concertó la impresión con el citado Alonso Gómez.

Ausente el secretario real en Portugal, Fernando Arenillas de Reinoso firmó en su nombre una capitulación con el impresor por la que éste se comprometía a tirar nada menos que 6350 ejemplares "del cathálogo de libros reprouados" y se le entregaron doscientos ducados de parte de Vázquez ${ }^{22}$. Una vez impreso, el propio Consejo de Inquisición estableció que cada pliego del Index se vendería a cinco maravedíes, una cifra relativamente alta para un volumen en cuarto, lo que elevaba aún más el posible beneficio final de una edición de más de seis mil ejemplares ${ }^{23}$.

La concesión a Mateo Vázquez de la licencia y privilegio del Index de 1583 se justifica "por lo que se ha ocupado, y trabajado en la ordenación dél" ${ }^{24}$. Es cierto que era habitual que los privilegios de impresión de textos de naturaleza normativa se concediesen a secretarios o escribanos reales, pero la gracia de Quiroga, tan generosa en términos económicos, merecería ser considerada también desde la perspectiva de la lucha política en la corte de Felipe II $^{25}$. Por otra parte, no debe extrañar que la publicación de un título de la naturaleza del Index no corriese por cuenta del propio Consejo. Aquel mismo año, Quiroga hacía imprimir las Constituciones Sinodales de su archidiócesis toledana y éstas aparecían en Madrid costeadas por el mercader de libros Blas de Robles ${ }^{26}$.

Sin duda, el interés demostrado por particulares que, como Barreira, Gravius o Robles, pagaban a su costa -expensis suis- impresiones y reimpresiones demuestra la existencia de un amplio y rentable mercado editorial que debía satisfacer al público, clerical o no, en sus necesidades devotas, espirituales o exegéticas, sin olvidar la fruición de otros géneros, como, por ejemplo, el hagiográfico, el cronístico o el poético.

21 Archivo Histórico Nacional, Madrid (AHN), Inquisición, libro 357, fols. 90v.-91r.

22 Al recibir esta cantidad para la impresión, entregada por Juan Fernández de Espinosa en nombre de Vázquez, Gómez da cuenta de la capitulación en Madrid a 3 de noviembre de 1582, Archivo Histórico de Protocolos de Madrid (AHPM), protocolo 1022, Juan Montero, fol. 660r.-v. Pérez PASToR, C.: Bibliografía madrileña o descripción de las obras impresas en Madrid (Siglo XVI), 3 vols., Madrid, Tipografía de los Huérfanos, 1891-1907, III, p. 496.

23 La tasa se fijó en Madrid, 2 de julio de 1583, Index, op. cit. (nota 20), al vuelto de la portada. La descripción bibliográfica canónica de la obra es: “ 4 - 96 hs. fols., más 6 de prels. sin numerar. - sign. $A$, *, $A-M$ - La $1^{\text {a }}$ de 4 hojas, la $2^{\text {a }}$ de dos, y las demás de 8", Pérez Pastor, op.cit. (nota 22), II, p. 87. Es difícil estimar los beneficios de correr con la impresión del Index de 1583, cuyo cuerpo principal es de doce pliegos, al no haber sido posible comprobar si su privilegio se extendía también al Index librorum expurgatorum (Madriti, 1584). En cualquier caso, sólo con la venta de la jornada de 1583 a 60 maravedíes cada cuerpo se trataba de un negocio de cientos de ducados.

24 Index, op.cit. (nota 20), preliminares sin foliar.

25 Sobre el acercamiento de Quiroga a Vázquez a comienzos de la década de 1580, precisamente con la mediación del Licenciado Arenillas, Pizarro Llorente, H.: Un gran patrón en la corte de Felipe II. Don Gaspar de Quiroga, Madrid, Universidad Pontificia de Comillas, 2004.

26 Impressas en Madrid, en casa de Francisco Sánchez. A costa de Blas de Robles, mercader de libros, en Corte. Sobre este librero, MoRisse, G.: "Blas de Robles (1542-1592) primer editor de Cervantes", en AndRÉs, P. (ed.): El libro antiguo español. VI. De libros, librerías, imprentas y lectores, Salamanca, UniversidadSEMYR, 2002, pp. 285-320. Ha de destacarse la importancia de este trabajo por el relieve que concede al negocio de "invertir en libros". 


\section{COSTEADORES DE IMPRESIONES Y MERCADO EDITORIAL DEL LIBRO RELIGIOSO}

Los que, para la alta Edad Moderna, calificaremos con el nombre genérico de costeadores eran particulares que se presentan, ante todo, pero no siempre, como libreros, impresores o mercaderes de libros y que, en principio, venían a adquirir las prerrogativas inherentes a los privilegios y licencias en vigor directamente de los autores o de sus poderhabientes. Solían hacerlo mediante un pacto negociado, por lo general en forma de concierto de cesión, en el que se fijaban las condiciones de su duración, normalmente por una sola vez, y su compensación económica y en especie, siendo habitual la entrega de una parte de los libros que llegasen a imprimirse. Por este traslado de dominio quedaban eximidos de tener que solicitar nueva licencia de impresión y se convertían en cesionarios de sus posesores por merced real, quienes renunciaban a utilizar tales derechos en aquellas condiciones que fijase el concierto de cesión. El siguiente caso puede ayudarnos a comprender el proceso.

El Espejo de consolación de tristes de Juan de Dueñas fue editado en numerosas ocasiones a lo largo del XVI, buena prueba de la aceptación de la obra del enardecido, y pronto sospechoso, fraile franciscano. Por merced real de 1582 [Lisboa, 6 de julio], el privilegio de impresión había sido prorrogado a la Orden de San Francisco del Reino de Toledo, en cuyo nombre había actuado Fr. Antonio Álvarez. A la altura de 1587, sin embargo, era el mercader de libros alcalaíno Diego Martínez quien actuaba como su cesionario en virtud de una escritura pública que le facultaba para que él, a su vez, cediera su poder de hacer imprimir y vender el Espejo al también librero Juan Boyer.

Así lo hizo Martínez en virtud de una escritura "de cesión, renunciación e traslado" otorgada en Medina del Campo el 30 de octubre de 1587. En ella se puede leer que:

[...] vos Juan Boyer, mercader de libros [...] os habéis convenido, concertado e igualado conmigo sobre y en razón de la dicha impresión en esta manera, que por que yo os dé licencia e ceda el derecho que tengo a la dicha impresión del dicho libro intitulado Consolación de Tristes para poder imprimir y vender seis tomos del dicho libro de la marca que quisiéredes por una sola impresión me avéis dado e pagado luego de presente quinientos reales en reales contados, e más me avéis de dar cien libros cumplidos acabados de la dicha impresión del libro [...] que son los que yo estoy obligado a dar a la orden de San Francisco de dicho Reino de Toledo ${ }^{27}$.

Convertido en nuevo cesionario de quienes seguían siendo beneficiarios del regio privilegio, Boyer hizo imprimir las seis partes del Espejo de consolación que circularon en dos volúmenes publicados "a su costa" 28 .

27 Pérez Pastor, C.: La imprenta en Medina del Campo, Madrid, Establecimiento tipográfico "Sucesores de Rivadeneyra", 1895, p. 163. Sobre las circunstancias de estos conciertos, MANO GonZÁLEZ, M. DE LA: Mercaderes e impresores de libros en la Salamanca del siglo XVI, Salamanca, Universidad, 1998, pp. 81-87; y Álvarez Márquez, C.: La impresión y comercio de libros en la Sevilla del Quinientos, Sevilla, Universidad, 2007.

28 DueÑAs, J. DE: Primera, segunda, y tercera [Quarta, quinta y sexta] parte del espeio de consolación de tristes, En Toledo por Pero Rodríguez, mercader y impresor de libros. A costa de Iuan Boyer, mercader de libros en Medina del Campo, 1591. 
Dadas las específicas condiciones de la autoría altomoderna, esta clase de concertaciones les permitía actuar de hecho como propietarios de un buen número de títulos que sólo llegaron, o con frecuencia volvieron, a las prensas gracias a ellos. Del mismo modo, los costeadores, siempre diligentes, anduvieron a la búsqueda de obras susceptibles de ser editadas de nuevo, bien porque careciesen éstas de privilegio, bien porque sus antiguos permisos de impresión hubieran fenecido, promoviendo ellos ante el órgano jurisdiccional competente la preceptiva autorización para volver a publicarlos.

No obstante, su ágil iniciativa pudo extenderse también a la realización de impresiones falsas o contrahechas a espaldas de autores o poderhabientes. Para evocar estas prácticas fraudulentas bastará con recordar un ejemplo célebre relacionado con el Índice de Fernando de Valdés.

Como se sabe, la tradición jesuita recogió desde antiguo que Francisco de Borja ingresó en el Índice porque unos "tratados espirituales" del Duque de Gandía habían sido impresos por "ciertos libreros" con añadidos de "Autores que tenían cosas que expurgar" ${ }^{29}$. El propio Borja le escribió a Diego Laínez [9 de septiembre de 1559] que "he sabido que a lo poco que yo tengo impresso me añadió un librero, por vender su hazienda, onze autores, callando el nombre dellos y intitulándolas todas a mí" ${ }^{30}$. Poco después, el mercader de libros alcalaíno Luis Gutiérrez fue señalado como quien "los añadió a su costa por hazer gran velumen, por que se vendiese por segunda parte del duque de Gandía" ${ }^{31}$.

Sea como fuere, en beneficio o en detrimento de los autores, la extensión de la financiación por editores particulares alcanzó incluso a los títulos más conspicuos que quepa imaginar, incluida la Biblia regia de Amberes ${ }^{32}$. Así, el Index portugués de António de Matos de Noronha, o de 1597, refleja en su misma portada que ha sido impreso por Pedro Craesbeeck "expensis Christophori Ortegae [Cristóvão Ortega] Bibliopolae" "33. La Censura generalis de biblias de 1554 se imprimió en Valladolid por cuenta de Francisco Fernández de Córdoba, a quien se le concedió licencia y privilegio ese mismo año, después de una complicada negociación mercantil en la que también entraron colegas de Salamanca y Medina ${ }^{34}$. Y la asendereada edición helmántica aparecida en 1584 de la Biblia sacra de Vatablo se hizo a expensas de Gaspar

29 Nieremberg, J. E.: Vida del santo padre, y gran siervo de Dios el B. Francisco de Borja, En Madrid, Por María de Quiñones, p. 163. Moreno, D.: "Francisco de Borja y la Inquisición", en La PARra, S. y ToldrÀ, M. (eds.): Francesc de Borja (1510-1572), home del Renaixement, sant del Barroc, Gandía, CEIC Alfons el Vell - Institut de Estudis Borgians - ACE, 2012, pp. 351-375.

30 Cito por CÁtedra, P. M.: Imprenta y lecturas en la Baeza del siglo XVI, Salamanca, Seminario de Estudios Medievales y Renacentistas-Sociedad de Estudios Medievales y Renacentistas, 2001, p. 109.

31 Ibidem, p. 114, n. 64.

32 Sobre la dimensión mercantil de las ediciones litúrgicas y escriturarias, Bowen, K. L., e IMHOF, D.: Christopher Plantin and Engraved Book Illustrations in Sixteenth-Century, Cambridge, Cambridge University Press, 2008. Para el conocido papel del hombre de negocios Luis Pérez en la empresa editorial de la Biblia de Amberes, Arias Montano, B.: Correspondencia conservada en el Museo Plantin-Moretus de Amberes, edición de A. Dávila Pérez, Madrid, Ediciones del Laberinto, 2002.

33 Index librorum prohibitorum, Olisipone, Apud Petrum Craesbeeck, 1597, Expensis Christophori Ortegae Bibliopolae. REgo, R.: Os índices expurgatórios e a cultura portuguesa, Lisboa, ICLP, 1982, p. 90.

34 Censura generalis contra errores quibus recens haeretici sacram scripturam asperserunt, Pinciae, Ex Officina Francis. Ferdinan. Corduben., s.a. [1554]. Licencia, Valladolid, 7 de agosto de 1554. Sobre las 
de Portonariis, Guillaume Rouillé y Benito Boyer ${ }^{35}$.

Por su parte, la primera edición castellana del Catechismus romano de Pío V, hecha en Medina del Campo en 1577, fue publicada a instancias del mercader de libros Benito Boyer, quien había obtenido licencia real en abril de $1575^{36}$. Del mismo modo, la historia editorial en la España de los Austrias de nada menos que los Canones et decreta Sacrosancti oecumenici \& generalis Concilii Tridentini no podría escribirse sin el concurso de los llamados costeadores.

El impresor complutense Andrés de Angulo obtuvo una licencia real para publicarlos en fecha tan temprana como el 21 de abril de 1564, en atención a que "vos teniades y auiades hecho traer los decretos del Concilio Tridentino con la confirmación de su Santidad, y en ello auiades gastado mucha suma de marauedís, y conuenía y era necessario que los dichos decretos se imprimiessen en estos nuestros reynos" ${ }^{37}$. De esta forma, las disposiciones tridentinas fueron impresas en Alcalá "xv kal. Iunii", por Pedro de Robles y Francisco Cormellas, a costa de los libreros Alonso Gómez y Juan de Escobedo ${ }^{38}$. Ese año comenzaba una larga tradición de ediciones de los cánones tridentinos en la que impresores y libreros fueron agentes y promotores principales ${ }^{39}$.

Por otra parte, si consideramos no las ediciones existentes, sino los expedientes de licencia y tasa de libros tramitados ante el Consejo de Castilla veremos corroborada la activa presencia de costeadores en su tramitación ${ }^{40}$. Pasemos revista, por poner sólo un ejemplo, a expedientes abiertos en las escribanías de cámara en el año 1612.

Encontramos, así, que el librero Antonio García solicitaba licencia para reeditar el Confesionario de Francisco de Vitoria, "el qual -a su juicio- es libro muy útil y provechoso y al presente ay mucha falta dellos" ${ }^{41}$; Antonio Ramírez, impresor, conseguía licencia para el citado Concilium Tridentinum ${ }^{42}$; y el mercador de libros

negociaciones y pujas para hacerse con la impresión, GonzÁlez Novalín, J. L.: El inquisidor general Fernando de Valdés (1483-1568). Su vida y su obra, Oviedo, Universidad, 2007 [1968], pp. 255-257.

35 Biblia sacra cum duplici translatione, \& scholiis Francisci Vatabli, Salmanticae, Apud Gasparem à Portonariis suis \& Gulielmi Rouillij Benedictique Boierij expensis, 1584. Para su historia editorial, GonZÁLEZ Novalín, J. L.: "Inquisición y censura de biblias en el Siglo de Oro. La Biblia de Vatablo y el proceso de fray Luis de León", en García de la Concha, V. y San José Lera, J. (eds.): Fray Luis de León. Historia, humanismo y letras, Salamanca, Universidad, 1996, pp. 125-144.

36 Catechismus ex decreto Concilii Tridentini ad parochos Pii Quinti Pont. Max. iussu editus, Methymnae Campi, Expensis Benedicti Boyerij, 1577. Licencia, Madrid, 26 de abril de 1575. Sobre la compleja historia de la recepción de la obra y los intentos de editarla en España, RodRíguez, P.: El catecismo romano ante Felipe II y la Inquisición española, Madrid, Rialp, 1998.

37 La licencia aparece en Canones et decreta Sacrosancti oecumenici \& generalis Concilii Tridentini, Compluti, Apud Petrum Robles \& Franciscum Cormellas. A costa de Juan de Escobedo, y Alonso Gómez libreros en corte, 1564, preliminares sin foliar.

38 Martín Abad, J.: La imprenta en Alcalá de Henares (1502-1600), 3 vols., Madrid, Arco/Libros, 1991, II, $n^{\circ} 597$.

39 Sin ánimo de exhaustividad, se relacionan algunas de las ediciones costeadas: 1564 (Alcalá, Valladolid, Salamanca, Valencia, Granada); 1568 (Salamanca); 1577 y 1583 (Medina); 1595 y 1598 (Salamanca); 1604 (Huesca, Alcalá); 1613 (Salamanca); 1618 (Valladolid); 1620 (Valencia, Zaragoza); 1629 (Zaragoza); 1647, 1654, 1655, 1657. 1660, 1661, 1666, 1671 (Madrid).

40 Sobre el proceso de los expedientes de imprenta en el Consejo, BouzA, op.cit. (nota 12).

41 AHN, Consejos suprimidos, leg. 44230, s. fol.

42 AHN, Consejos suprimidos, leg. 45797, s. fol. 
Juan Bonardo obtenía permiso para las Oraciones y ejercicios de devoción de Luis de Granada, exponiendo que "es de muy buena y sancta doctrina para todo género de gentes y de mucha utilidad y provecho del qual ay mucha falta"43. Por último, el arquero flamenco Cristiano Bernabé actuaba en relación con un librillo titulado "Práctica del arrepentimiento de los pecados del doctor Alonso de Arboleda, caballero de Belmonte" ${ }^{44}$; y un desconocido Gonzalo de Ayala solicitaba la licencia para Castilla en relación a un "epitafio de la sepultura del Padre Simó y una relación de Rafael Aznar impresos ya en Valencia" que habían llegado a sus manos ${ }^{45}$.

Es importante destacar que, salvo en el caso de Ayala que vio rechazada su propuesta, los otros peticionarios obtuvieron lo solicitado. Sin embargo, no es posible saber fehacientemente si llegaron a hacer uso o no de sus permisos de impresión, pues no se han localizado las ediciones para las que obtuvieron licencia, siendo posible que, a su vez, negociasen con ellas. Lo que esto revela es que, como sucede en otras materias y señaló magistralmente Jaime Moll $^{46}$, la reconstrucción de la historia editorial de la literatura religiosa impresa en los siglos XVI y XVII exige un análisis completo no sólo de las obras conservadas, sino también de los otros muchos títulos o ediciones cuya tramitación está documentada y que o han desaparecido o nunca llegaron a publicarse.

Como ya se ha indicado, quizá por su excesiva atomización frente a las poderosas compañías de editores instaladas en otros lugares de Europa, el estudio de la actividad de los costeadores en el mercado de libros de naturaleza religiosa está todavía por hacer de forma sistemática. No obstante, en su brillante monografía sobre Alonso Pérez de Montalbán, Anne Cayuela demuestra la importancia que las obras de religión, moral y poesía sagrada tuvieron en el desarrollo del significativo catálogo de ediciones costeadas por el librero madrileño ${ }^{47}$. Un acercamiento a la trayectoria editorial de otros costeadores puede resultar igualmente esclarecedor.

Activo en la Lisboa de Sebastián I, D. Enrique y Felipe II ${ }^{48}$, el librero Juan de Molina, conocido en Portugal como João de Espanha, fue corresponsal de Plantino, quien imprimió para él unas Horae Beatissimae Virginis Mariae en $16^{\circ}$ en cuyo pie se puede leer expresamente que han sido tiradas en Amberes "Pro Joanne ab Hispania" 49 . En tierras lusitanas, donde trabajó con frecuencia asociado con

\footnotetext{
43 AHN, Consejos suprimidos, leg. 45202, s. fol.

44 AHN, Consejos suprimidos, leg. 43789, s. fol.

45 AHN, Consejos suprimidos, leg. 47281, s. fol.

46 Moll, J.: “Aproximaciones a la sociología de la edición literaria”, en Jauralde, P., Noguera, P., y Rey, A. (eds.): La edición de textos. Actas del I Congreso internacional de Hispanistas del Siglo de Oro, Londres, Tamesis Books, 1990, pp. 61-68.

47 Cayuela, A.: Alonso Pérez de Montalbán. Un librero en el Madrid de los Austrias, Madrid, Calambur, 2005, pp. 96-103.

48 Deslandes, op.cit. (nota 1), pp. 79-83.

49 Dos cartas de Plantino a Molina fueron publicadas por Max Rooses en 1883, identificando también las Horae "Pro Joanne ab Hispania". Rooses, M. (ed.): Correspondance de Christophe Plantin, I, AntwerpenGent, J.E. Buschmann-A. Hoste, 1883, pp. 90-92 (Amberes, 7 de junio de 1567); pp. 138-139 (Amberes, 22 de julio de 1567); p. 91, n.1 (Horae in-16). Bowen e ImHof, op.cit. (nota 32), p. 165.
} 
Miguel de Arenas ${ }^{50}$, corrieron por su cuenta ediciones y reediciones de Bartolomeu dos Martires ${ }^{51}$, Nicolau Dias ${ }^{52}$, Heitor Pinto ${ }^{53}$, Luis de Granada ${ }^{54}$, Diogo do Rosário $^{55}$, Luis de Molina ${ }^{56}$, Bartolomé de Medina ${ }^{57}$ o Marcos de Lisboa ${ }^{58}$.

También es el caso de Antonio Coello, o Cuello, muy activo en la Castilla de comienzos del XVII, quien, además costear a Botero o Lope ${ }^{59}$, dedicó una parte de sus esfuerzos editoriales a la impresión de obras de autores eclesiásticos. En el decenio 1602-1612, financió la publicación de una variada serie de títulos de escritores como Pedro Mártir Coma ${ }^{60}$, Diego de la Vega ${ }^{61}$, Leandro de Granada ${ }^{62}$,

50 Este librero costeó diversas ediciones con Molina, véase infra a continuación. A la muerte de su socio, también lo hizo en solitario, como en BRuno, V. y VIEGAS, B.: Meditações sobre os mysterios da paixam, resurreiçam, e acensaõ de Christo Nosso Senhor, \& vinda do Spiritu Sancto, Em Lisboa, impresso por Pedro Crasbeeck. Aa custa de Miguel d'Arenas mercador de livros, 1601.

51 Bartolomeu dos Martires: Compendium spiritualis doctrinae, Olysippone, Excudebat Antonius Riberius, expensis Ioannis Hispani Bibliopolae, 1582.

52 Dias, N.: Livro do Rosayro de Nossa Senhora, Lixboa, Em casa de Francisco Correa, a custa de Ioam despanha, 1575.

53 PinTo, H.: Imagem da vida christam ordenada per dialogos, Em Lisboa, Impressos per Ioão de Barreyra á custa de Ioão de Espanha, mercador de libros, 1572; ID.: Segunda parte dos dialogos da Imagem da vida christam, Em Lisboa, Impressos per Ioã de Barreira. A custa de Ioão Despanha, mercador de libros, 1572. Molina costeó la reedición de 1575 de esta Segunda parte y la de 1580 de la primera, ambas por António Ribeiro.

54 Luis de Granada: Contemptus mundi [...]Añadiosele un breue tractado de Oraciones y exercicios de deuociõ muy prouechosos, Em Lixboa. A costa de Iuan Despaña, 1573; ID.: Primus [-secundus] tomus. Concionum de Tempore, Olysippone, In officina Ioannis Barrerij, expensis Ioannis Hispani Bibliopolae, 1575; ID.: Tertius tomus. Concionum de Tempore, Olysippone, Excudebat Antonius Riberius, expensis Ioannis Hispani bibliopolae, 1576; ID.: Ecclesiasticae rhetoricae, Olysippone, Excudebat Antonius Riberius, expensis Ioannis Hispani, 1576; ID.: Doctrina spiritual, S.l. [Lisboa], por Antonio Ribero. A costa de Iuan Despaña y Miguel Darenas Libreros, 1589.

55 Diogo do Rosário: Historia das vidas e feitos heroicos e obras insignes dos sanctos, A custa de Ioão Despanha \& Miguel Darenas liureiros. Em Lisboa, per Antonio Ribeiro, 1585.

56 Molina, L. DE: Concordia liberi arbitrij cum gratiae donis diuina, Olyssipone, Apud Antonium Riberium, expensis Ioannis Hispani et Michaelis de Arenas, 1588.

57 MedinA, B. DE: Breue instructión de cómo se ha de administrar el sacramento de la penitencia, En Lisboa, por Antonio Ribero. A costa de Iuã despaña y Miguel Darenas libreros, 1582.

58 Marcos de Lisboa: Primeira parte das Chronicas da Ordem dos Frades Menores do seraphico padre Sam Francisco, [Em Lisboa, per Antonio Ribeyro] A custa de Ioam de Espanha \& Miguel de Arenas Liureiros, 1587.

59 Botero, G.: Razón destado, En Burgos, En casa de Sebastian de Cañas : a costa de Pedro de Ossete y Antonio Cuello, libreros de Valladolid, 1603; Vega CARPIO, L. DE: Las comedias [...] recopiladas por Bernardo Grassa, En Valladolid, Por Iuan de Bostillo. Véndense en casa de Alonso Pérez y Antonio Cuello, 1605; y En Valladolid, Por Iuan de Bostillo, en la calle de Sámano. Véndense en casa de Antonio Coello, 1609. Es el librero quien firma la dedicatoria a Gabriel de la Nao, preliminares sin foliar. Sobre Coello, Roso Vega, A.: Impresores, libreros y papeleros en Medina del Campo y Valladolid. Siglo XVII, Valladolid, Junta de Castilla y León, 1994, pp. 83-86.

60 Coma, P. M.: Directorium curatorum o Instrución de curas, En Medina del Campo, Por Iuan Godínez de Millis. A costa de Pedro Ossete y Antonio Cuello, mercaderes de libros, 1602.

61 Vega, D. DE LA: Paraýso de la gloria de los sanctos[...] tomo primero [-segundo], En Valladolid, por Iuan de Bustillo, en la calle de Samano, A costa de Antonio Coello mercader de libros, 1607; Empleo y exercicio sancto, sobre los evangelios, En Burgos, En casa de Iuan Baptista Varesio. Acasta (sic) de Antonio Cuello, Mercader de libros, 1608. Hay edición con pie: En Valladolid, por Iuan de Bostillo. En la calle de Sámano. A costa de Antonio Coello, Mercader de libros, 1608.

62 Gertrudis la Magna - Leandro de Granada: Segunda y última parte de la admirables y regaladas reuelaciones de la gloriosa S. Gertrudis, En Valladolid, por Juan de Bostillo, en la calle de Sámano. A costa 
Luis de la Puente ${ }^{63}$, Ángel Manrique ${ }^{64}$, Antonio de Alvarado ${ }^{65}$ o Hernando de Castillo ${ }^{66}$.

Su condición de costeador le concedía la posibilidad de tomar decisiones importantes para la presentación final del libro. Por ejemplo, fue Coello quien dedicó al Doctor García Carreño el segundo tomo del Empleo y ejercicio santo de Diego de la Vega, que hizo imprimir en Burgos a su costa en $1608^{67}$. De la misma forma, a él, y no a los dominicos, corresponde la responsabilidad de que la nueva edición de la Primera parte de la historia general de Santo Domingo aparecida en Valladolid en 1612 vaya dirigida al Presidente de la Real Chancillería, Pedro de Zamora ${ }^{68}$.

Aunque en algunos casos quizá sea posible apreciar cierta huella de un afán espiritual particular en la toma de decisiones editoriales, los costeadores se guiaron fundamentalmente por su afán mercantil a la hora de pagar a sus expensas ediciones de obra nueva o reimprimir títulos de gran demanda. De esta forma, jugaron un papel importante en la definición de la oferta de títulos en circulación, pudiendo llegar a determinar quién, qué o en qué lengua alcanzaban las prensas.

Así, en 1620, Luis de la Puente presenta ante el Consejo de Castilla un memorial relacionado con "un libro que ha compuesto en lengua latina Sobre los cantares", para el que ya tenía la preceptiva licencia. Sin embargo, el jesuita debe solicitar un nuevo permiso para editar su Expositio in Canticum Canticorum, pero ahora en una imprenta foránea, alegando que no era capaz de concertarse con ningún costeador de los naturales que quisiese financiar su edición y que él no podía hacerlo con su propio peculio. El expediente contiene los testimonios de varios impresores madrileños que declararon que no les interesaba imprimir la latina Expositio de Luis de la Puente porque títulos como ése no tenían "despacho" "9.

Conviene insistir en que los que declaraban de esta manera tenían experiencia en la publicación para el mercado del libro religioso. Así, por poner sólo un ejemplo, Lorenzo de Ayala había financiado a su costa varias ediciones de Francisco Ortiz Lucio ${ }^{70}$

de Antonio Cuello mercader de libros. Véndese en su casa en la librería, 1607.

63 Puente, L. DE La: Guía espiritual. En que se trata de la oración, meditación y contemplación, En Valladolid, Por Iuan de Bostillo, en la calle de Sámano. A costa de Antonio Coello y véndese en su casa, 1609.

64 Manrique, A.: Sanctoral cisterciense, En Burgos, Por Iuan Baptista Varesio. A costa de Antonio Cuello mercader de libros, 1610

65 Alvarado, A. De: Arte de bien morir, En Valladolid, Por Francisco Fernández de Córdoua. A costa de Antonio Coello y Andrés López, 1611.

66 Castillo, H. Del: Primera [-segunda] parte de la Historia general de Santo Domingo y de su Orden de Predicadores, Impresso en Valladolid, Por Francisco Fernández de Córdoua. Véndese en casa de Antonio Coello y a su costa, 1612.

67 Coello, A.: [Dedicatoria] “A1 Doctor García Carreño, del Consejo de su Magestad, y su Alcalde de corte en la Real Chancillería de Valladolid", en VEGA, D. DE LA: Empleo y exercicio sancto, sobre los evangelios [...] tomo segundo, En Valladolid, por Iuan de Bostillo: En la calle de Sámano. A costa de Antonio Coello, Mercader de libros, 1608, preliminares sin foliar.

68 Coello, A.: [Dedicatoria] "A Don Pedro de Çamora Presidente de la Real Chancillería de Valladolid", Valladolid, 28 de febrero de 1612, en CASTILLO, op.cit. (nota 66), preliminares sin foliar.

69 AHN, Consejos suprimidos, leg. 45815, s. fol. Apareció en Parisiis, Sumptibus Dionysii de la Noüe, via Iacobaea, sub signo nominis Iesu, 1622. BouZA, op.cit. (nota 12), p. 72.

70 Había impreso a su costa las reediciones madrileñas de 1598 y 1599 del Compendio de todas las summas; y de 1599 y 1600 del Iardin de diuinas flores del fraile franciscano. 
y que, requerido para ocuparse de la impresión de la Expositio, expresamente, "dixo quél no se halla con poder para ynprimir tal libro [...] por no auer gasto en el reyno y ser más la costa que el provecho"71. En cambio, para obras como la del franciscano Ortiz Lucio, sí debió considerar que había suficiente "provecho" ante las expectativas de posibles ventas que abrían su género y, por supuesto, su lengua.

Como escribió Blas González de Ribero en la década de 1630, la incertidumbre dominaba el negocio editorial en el que se embarcaban los libreros, porque "el riesgo es de contado y el despacho al fiado"72. Por ello, no es de extrañar que se inclinasen por autores o materias que les permitiesen disminuir el riesgo y asegurarse el despacho, lo que supone que su papel fuera especialmente importante en el menos incierto mercado de las reimpresiones. Así, el ya citado Blas de Robles costeó las ediciones madrileñas de 1586 de la Historia de las cosas más notables, ritos y costumbres del gran Reino de la China de Juan González de Mendoza, publicadas tras el éxito de la princeps romana ${ }^{73}$. Del mismo modo, el mercader de libros Juan de Montoya financió en 1595 la reedición de las Obras de Pedro de Ribadeneira, pero formando una colección "porque quando andan sueltas y cada una por sí en libros pequeños fácilmente desaparecen y se pierden"74.

El papel de los libreros y mercaderes de libros en la introducción de obras impresas en talleres foráneos también fue capital y, por supuesto, no dejaba de estar presidido por su innegable voluntad de negocio. Así, en plena efervescencia por la beatificación teresiana de 1614, el librero Miguel de Sandi inició ante el Consejo Real en 1616 los trámites de nueva aprobación y fijación de la tasa que le permitiera vender en Castilla los ejemplares de la Vida de la santa madre Teresa de Jesús de Diego de Yepes que había comprado en Lisboa de la impresión de Pedro Craesbeeck ${ }^{75}$.

Un cuarto de siglo más tarde, en 1642, el mercader de libros Pedro Coello era quien seguía el mismo procedimiento para poder vender en Castilla los 700 "compendios de las cinco partes de Diana impresos en León" que había comprado y "pagado en plata"76. Se trataba del "compendium" de las Resolutionum moralium quae quinque tomis continentur de Antonino Diana hecho por Matteo Defendi e impreso en Lyon por los herederos de Gabriel Boissat y Laurent Anisson ${ }^{77}$. El avisado editor de Camões, Calderón y Quevedo buscaba proteger su inversión ante la aparición de una edición zaragozana de la misma obra sufragada por el también librero Pedro Escuer, quien, igual que él, quería beneficiarse de la fama del entonces celebérrimo teatino siciliano ${ }^{78}$.

71 AHN, Consejos suprimidos, leg. 45815, s. fol.

72 GonzÁlez de Ribero, B.: [Memorial] Los Libreros de los Reynos de Castilla y León por sí, y en nombre de todos los hombres doctos, y professores de Ciencias [...], S.1., n.i. [c. 1635], n.a., s. fol.

73 Impressa en Madrid, en casa de Querino Gerardo Flamenco. A costa de Blas de Robles librero, 1586; En Madrid, en casa de Pedro Madrigal. A costa de Blas de Robles, librero, 1586 [1587].

74 RibadeneiRA, P. DE: “Al Christiano y piadoso lector", en Las obras [...] agora de nueuo revistas y acrecentadas, [Madrid], En casa de la biuda de Pedro Madrigal. A costa de Iuan de Montoya Mercader de libros, 1595.

75 AHN, Consejos suprimidos, leg. 45555, s. fol.

76 AHN, Consejos suprimidos, leg. 46599, s. fol.

77 Defend, M.: Antonini Dianae [...] Resolutionum moralium [...] compendium. Lugduni, Sumpt. haered. Gabr. Boissat \& Laurentii Anisson, 1641.

78 La versión aragonesa apareció con el pie: Caesaraugustae, Apud Petrum Lanaja \& Lamarca, Regni Aragonum \& Universitatis Typ. A costa de Pedro Escuer, Mercader de libros, 1642. Sobre el librero, Velasco 
Antonino Diana (1585-1663) obtuvo notoriedad internacional como casuista gracias a la serie de doce tomos, o partes, de Resolutiones morales que publicó entre 1628 y 1656 y que se transformaron en una suerte de enciclopedia barroca, y probabilística, de la literatura de casos de conciencia ${ }^{79}$. Por ello, es comprensible la disputa entre costeadores por poder contar con un auctor cuyas obras eran continuamente demandadas por el mercado clerical católico. El mercader de libros madrileño Francisco de Robles intentó, incluso, ser el primer editor de una obra nueva del célebre teatino, la quinta parte de sus Resolutiones morales, y, de este modo, entrar en la respublica sacrarum litterarum internacional en la que los eruditos se mezclaban con impresores y libreros.

La aparición en Lyon en 1636 de la Resolutionum moralium pars quarta por Boissat y Prest había sido seguida por una serie de reediciones en distintos lugares de Europa, entre los que se encontraba Madrid, donde fue editada en 1637 a costa de Francisco de Robles y Pedro Coello ${ }^{80}$. La confianza en poder llegar a ser el primer editor de la esperada quinta parte llevó a Robles a escribir al casuista, quien le respondió desde Palermo en marzo de 1637 en estos términos:

Receví su caríssima carta i le doi muchas gracias por la estimación que haze de mi persona i de mis obras, aunque me pesa que me aia escrito tan tarde porque la mi quinta parte aún no está impresa si bien la e prometido al sr Cardenal Bixia para Lorenzo Duran natural de León de Francia, con que tampoco la e podido enviar a Boisat i Prest mis correspondientes de León que an impresso las otras partes, i assí juzgo que entre ellos se entenderán, pero si Dios me da vida no dejaré de inviarle a su tienpo un cuerpo y otra obrita que estoi haziendo estimando muchísimo el ser honrado en Reinos donde ai tan doctos a quienes io reverencio como muestro en mis escritos i afirmo que con todo esfuerzo haré que esta quinta parte, digo un cuerpo, vaia a manos de v.md. i ansí la encaminaré al señor Regente Don Josef de Nápoles por parte sigura i presto i me ará merced si mis obras todas están impresas en essos Reinos de llevarlas al dicho sr Regente don Joseph de Nápoles que pagará luego el prezio i ansimismo le ruego me aga merced de buscarme al Padre Urtado in primam et secundam et de Fide et spe etc y Armendárez las adiciones a la recopilación de las leis de Navarra, los quales libros entregará al dicho sr Regente que le pagará su coste con toda puntualidad. Io estoi haziendo reveer la quinta parte i copiándola para inviarla a Roma que la revean i espero que dentro de un año estará todo acabado i como e dicho si Dios me da vida no faltaré a servirle i entre tanto si me conoze ábil en alguna cosa de su servicio me mande. Palermo 17 de marzo 1637. Además de los sobredichos libros tendré gusto que Vs me invíe a Alfaro de officio fiscalis. Aficionadísimo siervo en el señor i servidor Dr. Antonino Diana ${ }^{81}$.

DE LA PEÑA, E.: Impresores y libreros en Zaragoza, 1600-1650, Zaragoza, IFC, 1998, pp. 356-364.

79 Burgio, S.: Teologia barocca. Il probabilismo in Sicilia nell'epoca di Filippo IV, Catania, Biblioteca della Società di Storia Patria, 1998; y "Antonino Diana e la rivolta del Portogallo: una testimonianza sulla crisi di metà Seicento", Siculorum Gymnasium. Rassegna della Facoltà di Lettere e Filosofia dell' Università di Catania, I-1-2 (1997), pp. 89-104.

80 [Matriti], Sumptibus Francisci Robles, et Petri Coello Mercatorum Librorum, ex typographia Maria de Quiñones, 1637. Presenta una dedicatoria de Robles a Pedro Marmolejo Ponce de León.

81 Carta de Antonino Diana a Francisco de Robles, mercader de libros, Palermo, 17 de marzo de 1637, AHN, Consejos suprimidos, leg. 24993-4. 
Esta circunstancia se expone con mayor detalle en una segunda carta, ahora de mayo de 1637 y dirigida al jesuita Gaspar Hurtado, donde Diana explicaba por qué no podía acceder a la petición del librero madrileño. En ella, señalaba que "la [Pars quinta] inviara de buena gana al sr Robles si no la ubiera prometido al sr Cardenal Bicia para Lorenzo Duran en León de Francia, por la qual causa no me e concertado con Boisat i Prost, que también me an pedido lo mismo por mano de otros señores cardenales" $"$.

Las cartas del teatino a propósito de su relación con Robles son sumamente ilustrativas sobre cómo funcionaba la particular república de las letras internacional. De un lado, la notable circulación de libros que llevaba aparejada, aquí, además de las del propio Diana, obras de Hurtado, Alfaro y Armendáriz ${ }^{83}$. De otro, la existencia de mediadores, que bien podían ser otros autores, como el Padre Hurtado, o potentados, a lo que parece el regente Josef de Nápoles en relación con Robles, algunos "señores cardenales" en abono de Boissat y Prost y, por último, nada menos que el cardenal Lelio Biscia en favor de Durand ${ }^{84}$. De esta forma la editio prima del esperado nuevo volumen quinto de Diana se publicó en Lyon en $1639^{85}$.

La madrileña, costeada por Francisco de Robles y Pedro Coello, vio la luz en Madrid en la imprenta de María de Quiñones, pero no pudo hacerlo hasta 1640 y como editio secunda ${ }^{86}$. Va encabezada por una singular dedicatoria de Robles al propio Consejo de Castilla en la que se evocan las "tempestades que he padecido antes de dar a la estampa esta quinta parte del Padre Diana" ${ }^{\text {" }}$, en alusión a un pleito que había abierto para frenar la introducción en Castilla de ejemplares de la edición lyonesa de Durand que pretendía el teatino genovés Benedetto Bozzomo. Para reforzar su derecho a imprimirla en exclusiva, Robles presentó entonces la licencia y privilegio por diez años que le había concedido el Consejo Real y, además, traducción de las cartas de Diana que testimoniaban los tratos que había tenido con el autor ya en $1637^{88}$.

Una vez retirados los ejemplares que debían ser entregados al Consejo y, en su caso, los que se solían dar a los autores o a sus poderhabientes por el concierto de cesión, haber costeado una edición implicaba, claro está, entrar en posesión de los ejemplares resultantes y pasar a disfrutar en exclusiva de su comercialización. El antes citado Francisco de Robles cifraba en más de nueve mil los volúmenes de ocho

82 Carta de Antonino Diana al padre Gaspar Hurtado, S.I., Palermo, 10 de mayo de 1637, AHN, Consejos suprimidos, leg. 24993-4.

83 Pedía libros como el Tractatus de fide, spe et charitate (Matriti: 1632) de Gaspar Hurtado; Aditiones sive anotationes Licenciati Armendariz ad suam Recopilationem Legum Regni Nauarrae ([Pompelonae]: 1617) de José de Armendáriz; o el Tractatus de officio fiscalis, deque fiscalibus priuilegiis (Vallisoleti: 1606) de Francisco de Alfaro.

84 Sobre la relación entre Durand y el cardenal Biscia, al amparo de Gabriel Naudé, MACLEAN, I.: Learning and the Market Place. Essays in the History of Early Modern Book, Leiden, Brill, 2009, pp. 151-152.

85 Diana, A.: Resolutionum moralium pars quinta [...] Editio prima, Lugduni, Sumpt. Laurent Durand, 1639.

86 DianA, A.: Resolutionum moralium pars quinta [...] Editio secunda, Matriti, Ex Typographiae Mariae de Quiñones. Sumptibus Francisci Robles \& Petri Coello Mercatorum Librorum, 1640.

87 Robles, F. DE: "Dedicatoria [...] al Supremo Consejo", en DianA, op.cit. (nota 86), preliminares sin foliar.

88 Preparo una edición de la correspondencia manuscrita de Antonino Diana custodiada en el AHN. En espera de ello, se ha optado ahora por la transcripción parcial de sus traducciones. 
títulos que había impreso y que todavía estaban en su poder en 1644. Se trataba de ejemplares de Esopo, Vives, Cicerón, Bravo y González de Villarroel, todos de gran consumo y fácil despacho, a los que se añadían tres obras de Antonino Diana: las partes cuarta y quinta y el compendio ${ }^{89}$.

Aunque los inventarios de libreros demuestran que también podían almacenar apenas uno o dos ejemplares de muchos de los títulos que tenían a la venta, lo cierto es que en ocasiones aparecen en ellos cantidades mucho más abultadas. Con frecuencia, se trata de obras que ellos mismos han costeado, como el citado Robles y sus casi mil quinientos cuerpos de Diana ${ }^{90}$. Por su parte, en 1609, el antes citado Antonio Coello tenía un fondo de librería en el que, al menos, se contaban 750 cuerpos de la Guía espiritual de Luis de la Puente, 300 del Paraíso de la gloria de los santos de Diego de la Vega, 200 de la Láurea evangélica de Ángel Manrique y 30 del Flos sanctorum del yermo de Juan Basilio Santoro ${ }^{91}$.

Este conjunto de más de mil volúmenes, al que hay que sumar 500 cuerpos de Comedias de Lope de Vega, también costeadas por Coello, fue destinado a pagar una de las cuatro casas de Martín de Córdoba que habían sido subastadas para hacer frente a las deudas de este librero vallisoletano. De hecho, se trataba de una suerte de intercambio similar a los que practicaban en los tratos que los libreros hacían entre sí, "para salir de algunos libros se truecan pliego por pliego, libro por libro, sin intervenir dinero alguno de parte a parte" 92 .

De esta forma, pagando con libros, Antonio Coello se hizo con una casa de su colega Martín de Córdoba entregándole a cambio cuerpos de comedias lopescas, pero, sobre todo, sus espirituales y devotos paraísos, guías, láureas y flores sanctorum. Pero, en este contexto del negocio editorial de obras de temática religiosa, lo más interesante es que en la subasta de las casas del librero vallisoletano en 1609 entraron también jesuitas y jerónimos, quienes ofrecieron pagar en libros y no en dineros las propiedades que pretendían adquirir.

\section{EN LIBROS Y NO EN DINEROS: JESUITAS Y JERÓNIMOS COMO MER- CADERES DE LIBROS EN LA VALLADOLID DE 1609}

Con la venta a pregones de cuatro casas a la calle de la Librería, Martín de Córdoba debía reunir dinero suficiente para pagar a sus acreedores, entre los que se encontraban algunos directamente relacionados con su negocio editorial. Así, Antonio López de Calatayud reclamaba una cantidad en relación con las Relaciones universales de Giovanni Botero, que había hecho traducir a Diego de Aguiar ${ }^{93}$; los benedictinos actuaban contra Córdoba porque no había cumplido con el contrato firmado con Fr.

\footnotetext{
89 AHN, Consejos suprimidos, leg. 47075, s. fol. La cifra total se elevaba a 9213 cuerpos.

90 De ellos, 1493 eran dianas: 704 Pars quarta; 103 Pars quinta; y 600 Compendium. Ibidem.

91 AHN, Consejos suprimidos, leg. 44210, s. fol. Remito a esta nota para las referencias en el texto a la venta de las casas del librero Córdoba.

92 GonZÁlez de RiBero, op.cit. (nota 72), sin foliar.

93 Impresso en Valladolid por los herederos de Diego Fernández de Córdoua. Véndense en casa de Martín de Córdoua, 1603.
} 
Pedro Vicente de Marzilla para la publicación de su Paraphrasis inter texta editioni vulgatae in Pentateuchum ${ }^{94}$; y el impresor madrileño Luis Sánchez pretendía cobrar sus buenos cien ducados para darse por satisfecho de la deuda de su colega vallisoletano, aceptando que se le pagase en libros no en metálico ${ }^{95}$.

Como se ha señalado, este sistema de pago en libros fue el que siguieron las dos órdenes religiosas que entraron en la subasta de casas de 1609. Actuando en nombre del escurialense monasterio de San Lorenzo el Real, Fr. Juan de Madrid pujó por una de las casas que había sido tasada en 24.000 reales. Por su parte, dos eran las casas que la Provincia de Castilla de la Compañía de Jesús quiso comprar a través de la procuración de Alonso Ramírez, quien se comprometió a entregar libros por valor de 54.431 reales.

Miles de ducados en miles de cuerpos que, sin duda, nos presentan a jesuitas y jerónimos como sendas órdenes depositarias de grandes fondos de librería susceptibles de ser movilizadas cuando se necesitase. Por otra parte, el contenido de las memorias declarando qué títulos y autores entregarían presentadas por Fr. Juan y el Padre Ramírez resulta muy elocuente de los intereses de ambas órdenes en materia de ediciones.

Los jerónimos del Escorial ofrecieron entregar una muestra del pequeño universo de títulos relacionados con la liturgia y el rezado que ellos controlaban, desde cuerpos de misales, horas, diurnos, libros de canto o martirologios romanos, en diferentes formatos, a simples pliegos de salterios, oficios de santos o calendarios para breviarios y otros impresos menores. El conjunto se elevaba hasta la enorme cifra de 7359 piezas para sólo 43 entradas. El único auctor que figuraba en la memoria era Fr. José de Sigüenza, de quien San Lorenzo ofrecía 100 volúmenes de la parte segunda de la Historia general de la orden jerónima (1600) a veinte reales cada cuerpo, 100 de la tercera (1605), a trece reales, y 233 de la Vida de San Jerónimo (1595), que era la primera parte, a sólo siete reales.

Conviene señalar que las órdenes y comunidades solían conservar conjuntos importantes de libros que habían sido compuestos por sus hijos. Aquí, los jerónimos laurentinos disponen de más de medio millar de cuerpos de las partes de la Historia de Sigüenza $(1595,1600,1605)$. Recuérdese, igualmente, que en 1587 Diego Martínez trasladó a Juan Boyer la obligación de entregar a los franciscanos toledanos cien ejemplares de la edición que como cesionario suyo pudiera hacer del Espejo de consolación de Dueñas ${ }^{96}$. Por su parte, Fr. Juan del Valle, de la comunidad de San Benito el Real de Valladolid, entregó para su venta a los libreros vallisoletanos Córdoba y Coello en 1604 seiscientos volúmenes de la Historia general de la Yndia Oriental de Antonio de San Román que había hecho imprimir Diego Pérez un año antes ${ }^{97}$.

La venta de cada cuerpo de los "descubrimientos y conquistas que han hecho las armas de Portugal en el Brasil y en otras partes de la África y del Asia" del monje be-

94 Terminó siendo publicada Salmanticae, In aedibus Antoniae Ramirez, viduae, 1610.

95 Sobre la actividad editorial de Córdoba, Rojo VEGA, op. cit. (nota 59), pp. 79-82.

96 Pérez Pastor, op.cit. (nota 27), p. 163.

97 En Valladolid, Por Luis Sánchez a costa de Diego Pérez, Mercader de libros, 1603. Sobre los tratos de los benedictinos de Valladolid con Pérez, infra nota 99. Sobre el librero, Rojo Vega, op.cit. (nota 59), pp. 174-176. 
nito se había fijado en diez y siete reales y en un año los libreros vallisoletanos habían despachado 500 "historias"98. Poco antes de partir hacia su obispado novohispano de Guadalajara, Fr. Juan aprovechó la ocasión para poner en orden sus negocios de librería y, así, liquidó sus cuentas con Córdoba y Coello, pero también con el citado Diego Pérez y Pedro de Escobar, también libreros de Valladolid ${ }^{99}$. Al menos Coello le pagó su deuda en "dineros y libros".

La oferta de librería, si vale la expresión, de que hizo gala la Compañía de Jesús en 1609 para adquirir las dos casas de Martín de Córdoba se elevaba a 5769 cuerpos correspondientes a 332 títulos distintos, de los cuales 132 habrían sido traídos de fuera del Reino. Éstos últimos se valoraban por libras, mientras que los volúmenes que tenían tasa lo hacían conforme al valor de ésta.

Frente al solitario Sigüenza de los jerónimos, la nómina de auctores jesuitas es absolutamente impresionante, lo que es elocuente ejemplo de la activísima implicación de los miembros de la Compañía en la escritura y publicación de libros. Como si la Provincia de Castilla dispusiese de una particular biblioteca de autores de la orden, el Padre Ramírez se comprometía a entregar cuerpos de un elenco de escritores que ya parece enorme a la altura de 1609.

Así, la memoria incluye obras que van de las Tragicae [32 cuerpos] de Luís da Cruz y el Cathechismus [25] de Edmond Auger a la Historia [6] y De rege [1] de Juan de Mariana o De disciplina christiana [16] de Bernardino Rossignoli, pasando por De perfectione [50] de Luca Pinelli, las Obras [12] y el Manual de oraciones [25] de Pedro de Ribadeneira, el Opus marianum [30] de Martin del Río y la Historia de las misiones [4] de Luis de Guzmán ${ }^{100}$. Algunas de las entradas están especialmente bien nutridas, como la correspondiente a Gaspar de Astete, quien cuenta con 300 "del matrimonio" y otros 300 "de doncellas y viudas"; Francisco de Toledo, con "600 sumas"; Benito Perera y sus 300 "Ad Romanos"; o Juan Bonifacio con 200 "de Beatae Virginis"101. Aunque el asiento más cuantioso, y el primero, de la memoria de Ramírez reza: "1200 Relación de Japón y china con carta 90 pliegos a 3 maravedíes 270 maravedíes 324.000".

98 Carta de pago de Fr. Juan del Valle para Antonio Coello, librero de Valladolid, Madrid, 13 de junio de 1607, AHPM, protocolo 3461, Juan de Mijancas, fols. 44r.-45v. También les había vendido cuatrocientos cuerpos de la Agricultura alegórica o espiritual del bernardo Diego Sánchez Maldonado, En Burgos, Por Iuan Baptista Varesio, 1603. La escritura de venta se había formalizado en Valladolid, 30 de agosto de 1604 y la liquidación de ejemplares vendidos el 31 de agosto de 1605. Cfr. RoJo VEGA, op.cit. (nota 53), p. 80.

99 Carta de pago de Fr. Juan del Valle para Diego Pérez, librero de Valladolid, Madrid, 13 de junio de 1607 , AHPM, protocolo 3461, Juan de Mijancas, fol. 46 r.-v. El benedictino era acreedor de 1800 reales; Carta de poder de Fr. Juan del Valle para Antonio Coello, librero de Valladolid, para que pueda cobrar en su nombre mil reales que le adeuda Pedro de Escobar, mercader de libros, Madrid, 13 de junio de 1607, AHPM, protocolo 3461, Juan de Mijancas, fols. 47 r.-48r.

100 Otros autores de la Compañía cuyas obras aparecen en la memoria son: Gaspar de Astete, Francisco de Toledo, Orazio Torsellini, Francisco Suárez, Francisco Arias, Juan de Polanco, José de Acosta, François Coster, Antonio de Torres, Bartolomé Bravo, Benito Pereira, Juan Bonifacio, Tomás Sánchez, Henrique Henriques, Juan Osorio, Juan Maldonado, Juan Azor, Manuel de Sa, Giulio Fazio, Antonio Possevino, Pedro da Fonseca, Jakob Spanmüller (Pontanus), Pedro Juan Perpiñá, Roberto Belarmino, Adriaan Adriansens, Vincenzo Bruni, Francesco Benzi, Jacobus Gretser, Francisco de Ribera o Pierre Thyraeus, sin olvidar los cursos del Colégio das Artes conimbricense.

101 Las obras eran éstas: Tratado del gobierno de la familia y estado del matrimonio; Tratado [...] y estado de viudas y doncellas [Astete]; Suma de casos de conciencia [Toledo]; Disputationes super epistola ad Romanos [Perera]; Historia virginalis [Bonifacio]. 
Si los libros movilizados por El Escorial provienen, claramente, de su privilegio sobre el nuevo rezado y la pertenencia a su comunidad del Padre Sigüenza, no ha sido posible dilucidar la procedencia del fondo de librería de los jesuitas. La circulación entre distintas provincias de impresiones de obras de miembros de la Compañía explicaría que Ramírez pudiera ofrecer en su memoria de 1609 ediciones de auctores jesuitas venidas de Francia, Países Bajos, Portugal, Italia o el Imperio. También sería posible explicar la presencia de textos que tienen una clara dimensión escolar y que podrían relacionarse con los colegios de la Compañía.

Por ejemplo, antes se ha mencionada la treintena de Tragicae de Crucius que podrían unirse ahora a las " 8 tragedias Senece 16 ", "1 Terencio con comento" e, incluso, a los Progymnasmata de Jacobus Pontanus [1]. Esto por no entrar en la larga serie de auctoritates clásicas que, junto a ortografías y gramáticas, se relacionan en la memoria, de Aristóteles a Quintiliano y Claudiano, pasando por, entre otros, Platón, Jenofonte, César, Ovidio, Salustio, Silio Itálico, Suetonio o Lucrecio, presente con 46 cuerpos in- $16^{\circ}$ de De rerum natura. A este respecto, por desgracia, no figura la Bibliotheca selecta de Possevino, autor del que sólo se puede encontrar el Judicium antimaquiavélico.

Pero las casas de Martín de Córdoba también serían pagadas con libros de escritores no pertenecientes a la Compañía de Jesús ni relacionados con sus intereses pedagógicos. Así, la presencia de autores de otras órdenes, como franciscanos, dominicos, agustinos, benedictinos o cartujos, es notable, como también es elocuente que el inventario desgrane entradas que ayudan a medir el calado de la que era, o quizá había sido, la espiritualidad jesuítica a la altura de 1609, como esos doce cuerpos del Confessionale de Girolamo Savonarola o los diez de la Theologia naturalis de Raimundo Sebunde. No obstante, siempre se podría argumentar, críticamente, que lo que hacía el Padre Ramírez era, precisamente, desprenderse de ellos.

Sin duda, reunir libros por valor de esos 54.431 reales -casi 5000 ducados- que valían dos de las casas de Martín de Córdoba en la calle de la Librería vallisoletana exigía agenciarse muchos cuerpos de libros, muchos autores, muchos títulos, propios y ajenos. Aparte de leerlos, escribirlos, aprobarlos, censurarlos, ordenarlos o enseñar con ellos, los jesuitas también negociaban con libros, incluso en cantidades de su trato más grueso.

Por otra parte, sin los mercaderes de libros e impresores una parte importante de la relación del clero con la cultura escrita no hubiera sido posible. Como se ha intentado demostrar, el papel de los costeadores que invertían en el suculento mercado editorial del libro religioso en el mundo ibérico de los siglos XVI y XVII fue mucho más relevante de lo que en principio se hubiera podido pensar. Y, sin duda, fenómenos como la edición y circulación del libro religioso deberían enfrentarse reservándoles un mayor espacio a sus iniciativas. 